\title{
DESIGN OF FUTURE SINGLE AISLE AIRCRAFT
}

\author{
RADULOVIC, A[nja]
}

\begin{abstract}
The following paper presents a model for airplane performance and tries to explain what happens in slatless configuration in order to reduce manufacturing costs. First the performance model with sensitivity analysis was carried out, which was followed by the investigation of high-lift systems of an aircraft, proposed wing configuration and estimated costs. Key words: aircraft, wing, slats, cost, performance
\end{abstract}

\section{INTRODUCTION}

Low-cost airliners have more passengers every day, and therefore a bigger contribution to the market. For customers, it is more important to pay less for the flight than ever before. There are many different ways of doing it, but the most important is not to decrease safety. One approach of reducing costs is manufacturing. In this paper, the author explains the proposition of slatless wing configuration.

The project was divided into two main parts. In the first part the airplane performance model based on balancing forces in all segments of flight was developed and verified. These forces are weight, lift, thrust and drag, as shown in Fig 1.

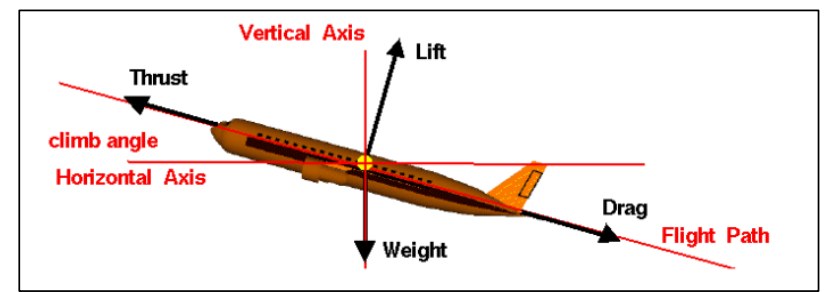

Fig. 1. Forces in flight

The model was based on the data of an Airbus A320 because this aircraft is very widespread among low-costs. They are presented in Tab. 1.

\begin{tabular}{|l|c|}
\hline overall length [m] & 37.57 \\
\hline geometric wingspan [m] & 34.10 \\
\hline wing area [m ${ }^{2}$ ] & 122 \\
\hline aspect ratio & 9.39 \\
\hline wing sweep (25\% chord) [deg] & 25 \\
\hline height [m] & 11.76 \\
\hline max cabin width [m] & 3.70 \\
\hline fuselage diameter [m] & 3.95 \\
\hline thickness-to-chord ratio & 0.153 \\
\hline engines (2x) & CFM International \\
& CFM56-5 series \\
\hline max operating Mach number & 0.82 \\
\hline max lift coefficient at takeoff & 2.56 \\
\hline max takeoff weight [tonnes] & 73.50 \\
\hline max landing weight [tonnes] & 64.50 \\
\hline max zero-fuel weight [tonnes] & 61 \\
\hline max fuel capacity [l] & 24210 \\
\hline
\end{tabular}

Tab. 1. A320 technical specifications

\section{PERFORMANCE MODEL}

The model was divided into five segments - takeoff, climbing, cruising, descending and landing. In order to make the pattern, these general assumptions were considered:

- No fuel is burnt during takeoff and landing

- No effects of the wind

- Takeoff and landing is at sea-level and ISA $+15^{\circ} \mathrm{C}$

- Lift is provided only by wings

- Drag is provided by wings, fuselage and tailplane

- No engine failure

The takeoff segment was considered to be only at sea-level, although the author is aware that climb-out is also considered to be a part of takeoff. Climbing was split in two parts due to different angles of climb. The first part of climbing occurred from 0 to $10000 \mathrm{ft}(3048 \mathrm{~m})$ and the second until $30000 \mathrm{ft}$ (9144m). In cruising, the plane is slightly gaining altitude until $35000 \mathrm{ft}(10668 \mathrm{~m})$. Descending is opposite of climbing, so it goes from final cruising altitude until sea-level. And finally, landing is the opposite of takeoff, occuring at sea-level. This is represented in Fig. 2.

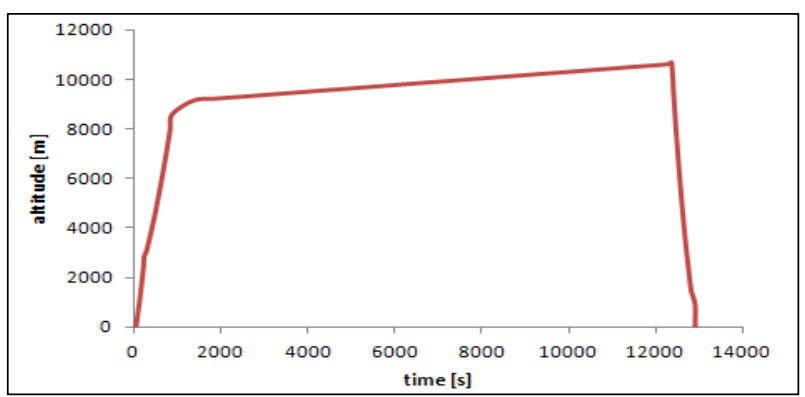

Fig. 2. Time vs. altitude, plotted in Excel

In order to make a model, several formulae were used for getting sufficient parameters for the following equations:

$$
\begin{gathered}
L=W \cos \varphi+m a_{v} \\
T=W \sin \varphi+D+m a_{h}
\end{gathered}
$$

where $\mathrm{L}$ stands for lift, $\mathrm{W}$ for airplane weight, $\varphi$ for path angle, a for acceleration ( $\mathrm{v}$ for vertical and $\mathrm{h}$ for horizontal component), $\mathrm{T}$ for thrust and $\mathrm{D}$ for drag.

The biggest challenge was to determine drag because it is provided not only by wings, but also by fuselage and tailplane. Other components, like landing gear, windshield etc. also affect drag, but their contribution is negligible for this model. In order to calculate drag from the equation

$$
D=\frac{1}{2} C_{d} \rho S v^{2}
$$

$\left(\mathrm{C}_{\mathrm{d}}\right.$ is drag coefficient, $\rho$ density, $\mathrm{S}$ the reference area and $\mathrm{v}$ velocity), $C_{d}$ of wings, tailplane and fuselage were determined 
using data, available in reliable sources. Mentioned information was partly analytical and partly based on experience. Wing drag was calculated as the sum of zero-lift drag, induced drag, wave drag, profile drag and interference drag. For the fuselage and tailplane, only zero-lift drag was considered. Other parts of drag were too small to affect the model's results.

After applying several calculations, the weight change in each segment of flight was determined. The weight of an aircraft during flight is changing due to fuel consumption, which depends on type of engine and Mach number. This was defined from experimental data. As a result, weight change was determined for every segment of flight.

When these parameters were calculated, the performance model was built and validated using different programmes (Piano X, EngineSim, etc.) and resources. Example: The contribution of zero-lift drag from wing, fuselage and tailplane was plotted in Excel (Fig. 3) and compared with references.

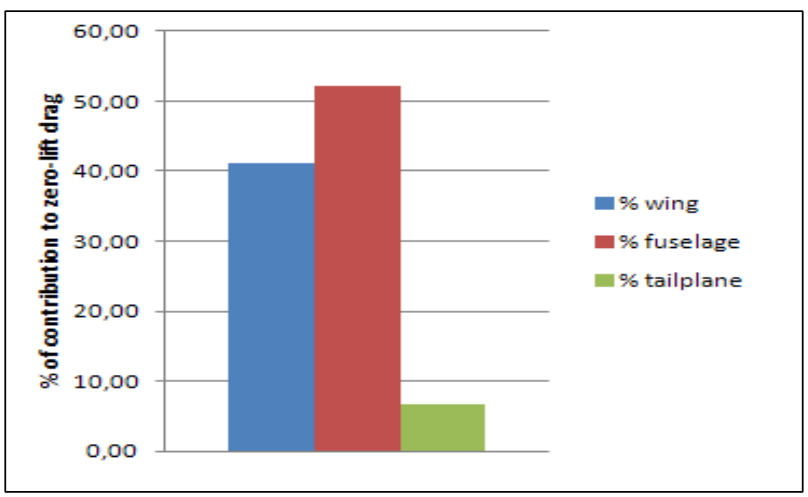

Fig. 3. Zero-lift drag contribution

\section{HIGH-LIFT SYSTEMS}

Multi-element high-lift systems are a necessity in order to allow airplanes to take off and land on runways that have acceptable length and they are not penalizing significantly cruise efficiency. High-lift systems on the Airbus A320 are single-slotted flaps with four different settings $\left(10^{\circ}, 15^{\circ}, 20^{\circ}\right.$ and $35^{\circ}$ ) and slats with one setting.

In order to see how a slatless configuration would affect aircraft's performance, the contribution of slats, flaps and wing itself was examined. Slats contribute much less to total lift than flaps, but still, for a configuration without slats the same wing would not provide enough lift. Therefore, the author decided to change the wing area by keeping the wingspan and changing the aspect ratio. During takeoff a flap deflection of $20^{\circ}$ was used.

After this, the lift coefficient for each flap setting was assumed. This led to the determination of a wing area that would provide enough lift without slats. It was concluded that a wing surface of $166 \mathrm{~m}^{2}$ would provide enough lift with selected flap settings $\left(20^{\circ}\right)$, which is a $36 \%$ increase. Moreover, the total dimensions of the wing were defined. In Tab. 2. the comparison between the original and proposed wing are presented.

\begin{tabular}{|c|c|c|}
\hline & original version & new version \\
\hline wing area $\left[\mathrm{m}^{2}\right]$ & 122 & 166 \\
\hline wingspan $[\mathrm{m}]$ & 34.10 & 34.10 \\
\hline aspect ratio [/] & 9.39 & 7.00 \\
\hline chord $[\mathrm{m}]$ & 3.63 & 4.87 \\
\hline
\end{tabular}

Tab. 2. Comparison between wing dimensions

\section{COST ESTIMATION}

From listed references it was estimated that the wing costs $175 \mathrm{USD} / \mathrm{ft}^{2}$ (1890 USD/m²). Flaps represent approximately $5.5 \%$ and slats $3.5 \%$ of the whole price of an aircraft.
According to information available, it was assumed that the version of A320 for low-costs is priced 73.2 mio USD. This leads to the conclusion that slats cost approximately 2.6 mio USD and flaps 4.0 mio USD. From the first estimation it was carried out that $122 \mathrm{~m}^{2}$ of wing (without flaps and slats) cost approximately 464000 USD. So the whole original version of the wing (wing itself, flaps and slats) costs approximately 7.1 mio USD.

The proposed version has larger wing area, but no slats. Calculating with the same numbers gave a result that wing itself (without flaps and slats) costs 628000 USD and the price of flaps stays the same as before, 4.0 mio USD. This leads to the approximation of 4.6 mio USD for this configuration, which reduces the price of the wing by 2.5 mio USD. This means that the new aircraft would no longer cost 73.2 mio USD, but 70.7 mio USD, which is $3.4 \%$ less than original version, taking into considerations that other parts of an aircraft remain the same.

But manufacturing costs are not the only that affect the price of an airplane. There are various other factors, like takeoff weight, aircraft performance, technological features, calendar time, market conditions and even governmental rules and regulations and legal issues. All of these were not considered here.

\section{CONCLUSION}

The main strategy of low-cost airliners is to reduce costs by excluding services that are not mandatory according to safety regulations. These are for example check-in luggage, on-board meals, seat choice and check-in at the airport. All of these are additional services and can be booked for extra payment. But this is not the only way to minimize expenses - they could be also reduced in manufacturing. If the wing was increased by $36 \%$, the expenses of an aircraft would be reduced by around $3.5 \%$.

In this paper only the manufacturing costs of a wing is considered, but further research should be done. Before applying the proposed configuration, not only the effect on environment, difference in burnt fuel and time should be investigated, but also analyses with more developed programmes, like computational fluid dynamics, should be carried out.

\section{ACKNOWLEDGEMENTS}

I would like to thank DAAAM International for giving me an opportunity to be a part of the symposium. Furthermore, I would like to express my sincere gratitude to my parents and sister for giving me support and help when needed.

This paper is the result of an individual research project at Cranfield University, but for this occasion it has been developed by the author alone.

\section{REFERENCES}

Evans, S. D. (2010). Design for Inner Wing in Composite, Cranfield University, Cranfield

Radulovic, A. (2010). Design for Manufacture of Future Single Aisle Aircraft, Cranfield University, Cranfield

Roskam, J. (1990). Airplane Design. Part VIII: Airplane cost estimation: Design, Development, Manufacturing and Operating, The University of Kansas, ISBN 1-884885-551, Kansas

Roskam, J.; Lan, C.T. (1997). Airplane Aerodynamics and Performance, Design, Analysis and Research Corporation (DARcorporation), ISBN 1-884885-44-6, Kansas

*** (2006) http://www.airbus.com - Airbus, Accessed on: 2011-06-13

*** (2006) http://www.grc.nasa.gov/ - NASA Glenn Research Center, Accessed on: 2011-08-27 